\title{
ESTRUCTURAS DE PESCA EN EL CANAL BEAGLE
}

\author{
MARTIN VÁZQUEZa \& FRANCISCO ZANGRANDOa
}

\section{RESUMEN}

En este trabajo se analizan estructuras de rocas emplazadas en el intermareal e interpretadas como corrales de pesca, constituyendo los primeros hallazgos documentados de su tipo para la costa sur de Tierra del Fuego. Si bien entre los casos analizados las características constructivas y los materiales utilizados presentan variabilidad, posiblemente vinculados a situaciones locales, las condiciones de emplazamiento y algunos aspectos morfológicos sugieren un cierto grado de estandarización. Se discute la información obtenida sobre estas estructuras con relación a las descripciones etnográficas y se analizan sus implicancias en el contexto de la evidencia arqueológica regional.

Las dificultades para su datación absoluta y la escases de evidencia contextual asociada a estas estructuras limita sensiblemente las posibilidades interpretativas acerca del rol que esta tecnología habría tenido a lo largo de la secuencia arqueología del canal Beagle. No obstante, el progresivo elevamiento de las costas por efecto de la glacioeustacia y del ascenso tectónico, conjuntamente con la localización de estas estructuras en el intermareal sugiere que los casos aquí presentados corresponderían a momentos finales del Holoceno. Por tanto, se plantea una potencial vinculación con el proceso de intensificación propuesto para momentos tardíos en el área.

PALABRAS CLAVE: Patagonia, Tierra del Fuego, tecnología de pesca, estructuras de rocas, canal Beagle, intensificación de la pesca, Holoceno tardío.

\section{FISHING STRUCTURES IN THE BEAGLE CHANNEL}

\begin{abstract}
We report first evidences of rock structures located in the intertidal zones of the southern coast of Tierra del Fuego. These structures are interpreted as fishing weirs. The structural characteristics and their raw materials vary among the different cases, possibly in relation to the local availability. However, site conditions and main morphological features suggest a high degree of standardization. The information obtained from these structures is analyzed in relation to the ethnographic descriptions, and

a Centro Austral de Investigaciones Científicas (CADIC-CONICET). Bernardo Houssay 200. CP: 9410. Ushuaia. Argentina. vazquezmartin68@gmail.com, panchozan@yahoo.com.ar
\end{abstract}


their implications for the prehistory are discussed in the context of the regional archaeological evidence.

The difficulties for direct radiocarbon analyses of these structures and the poor contextual evidence associated with them restrict the interpretation of this technology. However, the variations of the coastal geomorphology and the current location of these structures in the intertidal suggest that the cases presented in this paper could correspond to the most recent period of the Late Holocene. The relative temporal assignment to this period supports the idea that the adoption of this technology would have been part of the intensification process of fishing established for the region.

KEY WORDS: Patagonia, Tierra del Fuego, fishing technology, rock structures, Beagle channel, fishing intensification, Late Holocene.

\section{INTRODUCCIÓN}

Las evidencias de obtención y consumo de peces en Tierra del Fuego pueden rastrearse hasta el Holoceno medio, tanto en los contextos de la costa sur de Tierra del Fuego (p.e. Segundo Componente de Túnel I ca. 4500-6400; Capa K, L y M de Imiwaia I, ca. 4900-5900 y Bahía Valentín Sitio 11 ca. 5900-4500; Orquera \& Piana, 1999a; Orquera et al. 2011; Zangrando, 2009a; Vázquez et al. 2011), como en sitios del norte de la isla como Marazzi 1 y Rio Chico 1, datados hacia los 5500 y 5800 años AP respectivamente (Morello et al. 1999; Torres, 2009; Santiago, 2013; Santiago et al. 2007). Hacia momentos tardíos la pesca se torna más gravitante para la subsistencia en todo Tierra del Fuego (Torres, 2009; Zangrando, 2009a; Zangrando \& Tivoli, 2015). Para el canal Beagle, Zangrando (2009a, 2009b) propone la existencia de un proceso de intensificación de la pesca durante los últimos 1500 años, evidenciado por un significativo incremento tanto en la abundancia relativa de restos de peces como en la diversidad taxonómica de los conjuntos ictioarqueológicos.

Los corrales de pesca y estructuras similares constituyen un rasgo tecnológico recurrente de los paisajes culturales en todo el litoral pacífico sudoccidental, desde Chiloé hasta Tierra del Fuego. Su existencia ha sido documentada arqueológicamente en Chiloé e islas adyacentes (Álvarez et al. 2008; Munita et al. 2004; Skewes et al. 2012) y en menor medida en el Archipiélago de los Chonos (Reyes et al. 2011), en el Seno Skyring (Legoupil, 2000), en el sector occidental del Estrecho de Magallanes (Morello et al. 2008), en las costas de bahía Inútil al norte de Tierra del Fuego (Massone et al. 2003; Torres 2009) y en Isla Navarino (Furlong, 1917; Constantinescu, 2005; Massardo \& Rozzi, 2006; Ricardo Álvarez com. pers. 2013; Denis Chevallay com. pers. 2013). También en la vertiente atlántica de norpatagonia se ha registrado la presencia de estructuras de piedra en sectores intermareales del Golfo de San Matías (Cardillo \& Scartascini, 2016).

Por otra parte, las fuentes históricas y etnográficas informan sobre el uso de esta tecnología de pesca por los pueblos originarios que ocuparon distintas regiones del archipiélago patagónico. Los Hulliches, en el archipiélago de Chiloé, con una economía orientada a la producción agrícola, complementada con la pesca y la recolección de mariscos (Munita et al. 2004). Los Chonos en la región de la Península de Taitao y Golfo de Penas y hacia el extremo sur los Kawesqar y Yámanas; los últimos tres con estrategias de subsistencia fuertemente vinculadas con el mar (Emperaire, 1963; Bridges, [1947] 2000; Orquera \& Piana, 1999b). Para las sociedades Yámana se dispone de una serie de datos sobre la utilización y modo de funcionamiento de estructuras de pesca, aunque estos no son abundantes (Bridges, [1947] 2000; Gusinde, 1986; Martial et al. 2007; Lothrop, 1928); no obstante, hasta el momento solo existían escasas menciones de emplazamientos con este tipo de rasgo entre el canal Beagle y el Cabo de Hornos (Furlong, 1917; Constantinescu, 2005).

Los corrales de pesca son estructuras de piedras, ramas, estacas o una combinación entre estas que forman parte de una tecnología pesquera especializada. Su funcionamiento consiste en actuar como trampas al ser inundadas 
por el ciclo diario de las mareas, impidiendo el escape de los peces con la bajamar. La eficiencia de estas tecnologías dependerá tanto de las características constructivas propias del corral o dique, así como del conocimiento de la etología de las presas y del ambiente (Munita et al. 2004; Álvarez et al. 2008). Este tipo de tecnología, con muy diverso grado de complejidad, ha sido utilizada a lo largo del mundo por distintas sociedades tanto en ambientes marinos como de agua dulce. En Europa los tipos más tempranos pueden rastrearse hasta el Mesolítico (Pedersen, 1995), por ejemplo los diques identificados en el sitio de Tybrind Vig, en Dinamarca, fechado entre 6600 y 5200 años AP y vinculado al periodo Eterbolle (Andersen, 1995; Pikcard \& Bonsall, 2007). Asimismo, Malm (1995, p. 391) sugiere que este tipo de tecnología habría existido en muchos de los emplazamientos costeros vinculados con dicha cultura. Para tiempos relativamente recientes -entre el Medioevo y el siglo XIX- en las costas galesas se reporta una gran diversidad de estructuras pesqueras, muchas de ellas relacionadas con establecimientos religiosos dedicados a la pesca de arenques (Bannerman \& Jones, 1999). En la costa noroeste de América del Norte, desde Oregón hasta Alaska, se han identificado numerosos sitios con evidencias de tecnologías pesqueras de este tipo con fechas que van desde los 5.000 años AP hasta momentos históricos (p.e. Mobley \& McCallum, 2001; Moss \& Erlandson, 1998; Moss et al 1990). También en América del Norte, en las regiones de los grandes ríos del centro este, durante el periodo Arcaico fueron construidas y utilizadas grandes trampas de pesca (Johnston \& Cassavoy, 1978; Petersen et al. 1994), algunos casos incluso emplazados en sectores de la costa Atlántica, como las estructuras de postes y ramas excavadas en la actual ciudad de Boston, datadas entre los 5300 y 3700 años AP (Decima \& Dincauze, 1998). Australia es otro de los espacios donde los cazadores-recolectores han hecho un extenso uso de diques y trampas de pesca en diversos ambientes, tanto en el litoral marítimo como en ríos del interior. Entre estas se incluyen complejas estructuras de piedra como las del lago Condaha en el sudeste australiano, para las cuales se obtuvieron dataciones de hasta
6600 años AP (McNiven et al. 2012), o en el complejo de Ngembath, con una extensión de más de un kilómetro (Nutley, 2006). En general la puesta en práctica de estrategias de pesca masiva de este tipo implica una alta inversión de trabajo en la elaboración y mantenimiento del dique o corral, así como la participación de gran cantidad de personas, tanto durante su construcción, como en los procedimientos de pesca propiamente dicho. No obstante, la tasa de retorno por evento de captura se presume también elevada.

En la región del canal Beagle, pese a que existían algunas menciones en fuentes etnohistóricas sobre el uso de este tipo de artes de pesca, hasta el momento la existencia de diques o corrales no había sido registrada arqueológicamente en la costa sur de Tierra del Fuego. En este trabajo damos a conocer los primeros datos e interpretaciones sobre la localización de esta tecnología de pesca en la margen norte del canal Beagle.

\section{ANTECEDENTES}

\section{Información etnográfica}

Si bien existen abundantes referencias en la información etnografía y etnohistórica sobre el uso de corrales de pesca a lo largo del litoral pacífico sur (para una revisión ver Álvarez et al. 2008, pp. 127-147), las alusiones al uso de esta tecnología son menos recurrentes al sur de la Isla Grande de Tierra del Fuego (Orquera \& Piana, 1999b). No obstante, aunque escasa, esta información no deja de ser útil para las posibles interpretaciones sobre el funcionamiento de las estructuras que serán descriptas en este trabajo.

Lucas Bridges en el "Ultimo Confín de la Tierra" ([1947] 2000) describe estas estructuras y su forma de uso:

Para atrapar peces como el pejerrey y el róbalo, tenían otro sistema, en el que participaban todos los indigenas con gran alegría. Durante la pleamar, esos peces se internan en las angostas ensenadas que abundan en la región; cerca de donde desembocan, hay murallas de piedra construidas por 
los antiguos moradores del país, interrumpidas por espacios en el centro. Estas murallas están a un metro poco más o menos por debajo del agua durante la marea alta. Días antes de la pesca, los indios recogen gran cantidad de ramas, y cuando el agua sube, con mucho cuidado para no alarmar a los peces, las colocan tupidamente sobre las murallas y las sujetan con piedras. El agua pasa a través de las ramas al bajar la marea; en el centro de la muralla siempre hay una brecha que obstruyen con una red de fibra o con ramas. Los peces, impedidos de avanzar, buscan para huir la falla en la barricada, pero alli un indigena los espera con su arpón para impedirles escapar. Por este procedimiento puede obtenerse una tonelada o más de pescado de una sola vez, pero pasará mucho tiempo antes que tal cantidad de peces se junten de nuevo en la misma ensenada. (Bridges, [1947] 2000, p. 95, el resaltado es nuestro).

Por su parte Martin Gusinde (1986) ofrece una descripción muy congruente con la recién presentada:

Excepcionalmente los hombres arman nasas. Se deciden a hacerlo cuando varias familias están reunidas y es imposible continuar viaje, a la vez que acecha el hambre. Un úmmaku, wuepà es un enrejado que se arma sin mucho esmero; consiste en garrotes cortos hundidos en la tierra y varillas de cierta longitud trenzadas entre ellos y rellenas de manojos compactos de desbrozo. Nunca sobrepasa al metro de altura. Se colocan en bahías estrechas o, mejor aún, en arroyos angostos que desembocan en un ancho canal. Según cuál sea el nivel de las aguas en el curso de la pleamar, cuando ésta alcance su punto más alto, sólo se rellena el trenzado entre los garrotes colocados anteriormente con hojas y leña menuda o se coloca simplemente una pequeña pieza sobrepuesta que abarque todo el largo de la valla ya levantada. Si las condiciones son otras, se deja abierta la parte central, obturándose cuando se inicia la bajamar, ya sea que la nasa sea ancha o angosta. Cuando el mar está en su punto más bajo los peces quedan apresados en ella y pueden atraparse con la mano o matarse a golpes. El uso de nasas es muy poco frecuente pues, como me dijeron, su armado resulta incomodo y no promete un éxito seguro (Gusinde, 1986, p. 534535 , el resaltado es nuestro).

En la siguiente cita, Hyades y Denniker (Martial et al. 2007) aportan un dato de segunda mano y cuya alusión a "todos los pueblos marítimos del continente austral" resulta demasiado vaga, pudiendo referirse a grupos que habitaron otros sectores más septentrionales del archipiélago sudamericano. A continuación -también de segunda mano- toman el dato de Bridges, pero afirman no haber visto nada que recordara estos corrales. Años después Lothrop (1928) solo hace referencia a esta cita de Hyades y Denniker.

En el Voyage de Freycinet alrededor del mundo en el Uranie, se lee que todos los pueblos marítimos del continente austral usan corrales de pesca, en los ríos y en las entradas de mar a través de la tierra, corrales "construidos ya sea con piedras colocadas unas al lado de las otras, ya sea con postes bastante apretados como para impedir que el pez que entra no pueda salir". No vimos nada que recordara los corrales de este tipo, pero el Señor Bridges afirma que los Fueguinos atrapan peces en caletas por medio de represas formadas con ramas de árbol (Martial et al. 2007, pp. 110).

También resulta interesante mencionar las escuetas, y algo ambiguas, menciones de Charles Wellington Furlong (1917) en su descripción del asentamiento yámana de la bahía Wullaia, sobre el canal Murray en la costa oeste de la isla 
Navarino. Si bien, el análisis de esta referencia por si sola podría dejarnos con alguna duda sobre la asignación de estas estructuras a una trampa de pesca, la información y fotografías suministrada por el Sr. Denis Chevallay despejan toda duda sobre su asignación, por lo cual sería el único caso en el cual la existencia de esta tecnología fue determinada para una localidad específica, ya que en ninguno de los casos anteriores los autores referencian geográficamente sus descripciones.

\section{A number of fresh-water streams} pass through the camp site, while remnants of stone fish traps and canoe runways, cleared of stones, can be seen at low tide (Furlong, 1917, pp. 180, el resaltado es nuestro).

Además en Fig. 6 (p. 179) mapea dos estructuras paralelas de piedra en la boca de una ensenada que interpreta como "Fish-Traps", aunque deja abierta la posibilidad de que en se traten de embarcaderos de canoas.

En general pueden destacarse ciertas similitudes entre las descripciones de Bridges y Gusinde. En primer lugar la descripción del funcionamiento del sistema es coincidente $y$ ambos mencionan la participación de todo el grupo en la construcción del dique, así como en la acción de la pesca propiamente dicha. También coinciden en el tipo de emplazamiento, para Bridges son "ensenadas angostas" y para Gusinde "bahías estrechas o, mejor aún, en arroyos angostos que desembocan en un ancho canal". Respecto de la abertura en la parte central de la estructura, Bridges menciona que "en el centro de la muralla siempre hay una brecha" que interrumpe la continuidad de la trampa, pero la descripción de Gusinde, aunque sin entrar en mayores detalles, trasluce la existencia de estructuras con o sin esta abertura dependiendo de las condiciones, lo que sugiere la

1 En el texto original en inglés los términos utilizados son "Mullet and Smelt" (Bridges, 1947, p. 99). Si bien el término ingles más comúnmente utilizado para designar al róbalo (Eleginops maclovinus) es "blennie", "mullet" también es aceptable aunque podría referirse a otras clases de peces como perciformes o salmónidos, existencia de al menos dos tipos. Si bien Bridges, a diferencia del resto de los autores que enfatizan la utilización de varas y ramas, es el único en caracterizar estas trampas como "murallas", lo que sugiere la idea de construcciones de rocas apiladas y encastradas de cierta altura, coincide con Gusinde en que estas estructuras de piedra deben ser complementadas con ramas sujetadas con piedras. A esta coincidencia debe agregarse la mención de Furlong que interpreta un caso de los observados en Wullaia como "Stone Fishtraps".

Otro punto interesante con relación al aspecto constructivo son las referencias a la altura de la trampa. Gusinde es más explícito al mencionar que estos enrejados no sobrepasan el metro de altura, en cambio Bridges explica que estas murallas quedan aproximadamente un metro por debajo de la línea de alta marea. Teniendo en cuenta la baja amplitud de mareas que caracteriza al canal Beagle, esta estimación de Bridges denota que las murallas que menciona tampoco podrían haber sido muy altas.

Respecto del tipo de presas, solo en la cita de Bridges se hace mención a las especies obtenidas con estas técnicas de pesca refiriéndose a robalos y pejerreyes ${ }^{1}$, es de destacar que estas dos especies presentan hábitos gregarios y costeros, y por ende compatibles con la técnica de captura por medio de diques o corrales. Por otra parte la observación de que "un indígena los espera con su arpón para impedirles escapar", hace suponer que podría tratarse de róbalos grandes, más que de pejerreyes. Igualmente son sugerentes las menciones de Gusinde sobre el carácter excepcional de esta forma de pesca y su puesta en práctica frente a situaciones de hambruna o la imposibilidad de desplazarse, así como el dato mencionado por Bridges sobre el largo tiempo que debería esperarse para volver a utilizar estos sistemas en un mismo lugar.

Sólo Bridges aporta observaciones relacionadas con los tiempos implicados en la

sin embargo pensamos que esto es poco probable, más aun tomando en consideración la coexiencia de la denominación de "Falkland mullet" para la misma especie. El caso de la acepción de "smelt" como pejerrey no es tan ambigua y es de uso frecuente, aunque la más comúnmente utilizada es "silverside". 
construcción y uso de estas estructuras. Por un lado menciona que las estructuras habrian sido construidas por los "antiguos moradores del país", lo que sugiere cierta antigüedad y recurrencia en su utilización. Por otro lado, ya refiriéndose a los tiempos implicados menciona que "Días antes de la pesca, los indios recogen gran cantidad de ramas..." denotando cierta programación para su uso.

Por último cabe agregar una mención de Carlos Gallardo, que si bien se refiere a los Selk'nam no deja de ser sugerente, cuando en relación con la confección y utilización de redes menciona: “... representa un trabajo enorme, razón por la cual hay pocas y los indios prefieren pescar en sitios especiales en que les basta colocar unos obstáculos hechos de ramas" (Gallardo, 1998, p. 204).

\section{Casos arqueológicos}

Los corrales de pesca han sido registrados en varios sectores costeros de Isla Navarino, aunque por el momento se encuentran escasamente documentados. El caso mejor conocido es el descripto inicialmente por Furlong (1917) en bahía Wulaia, sobre la costa oeste de Navarino (ver

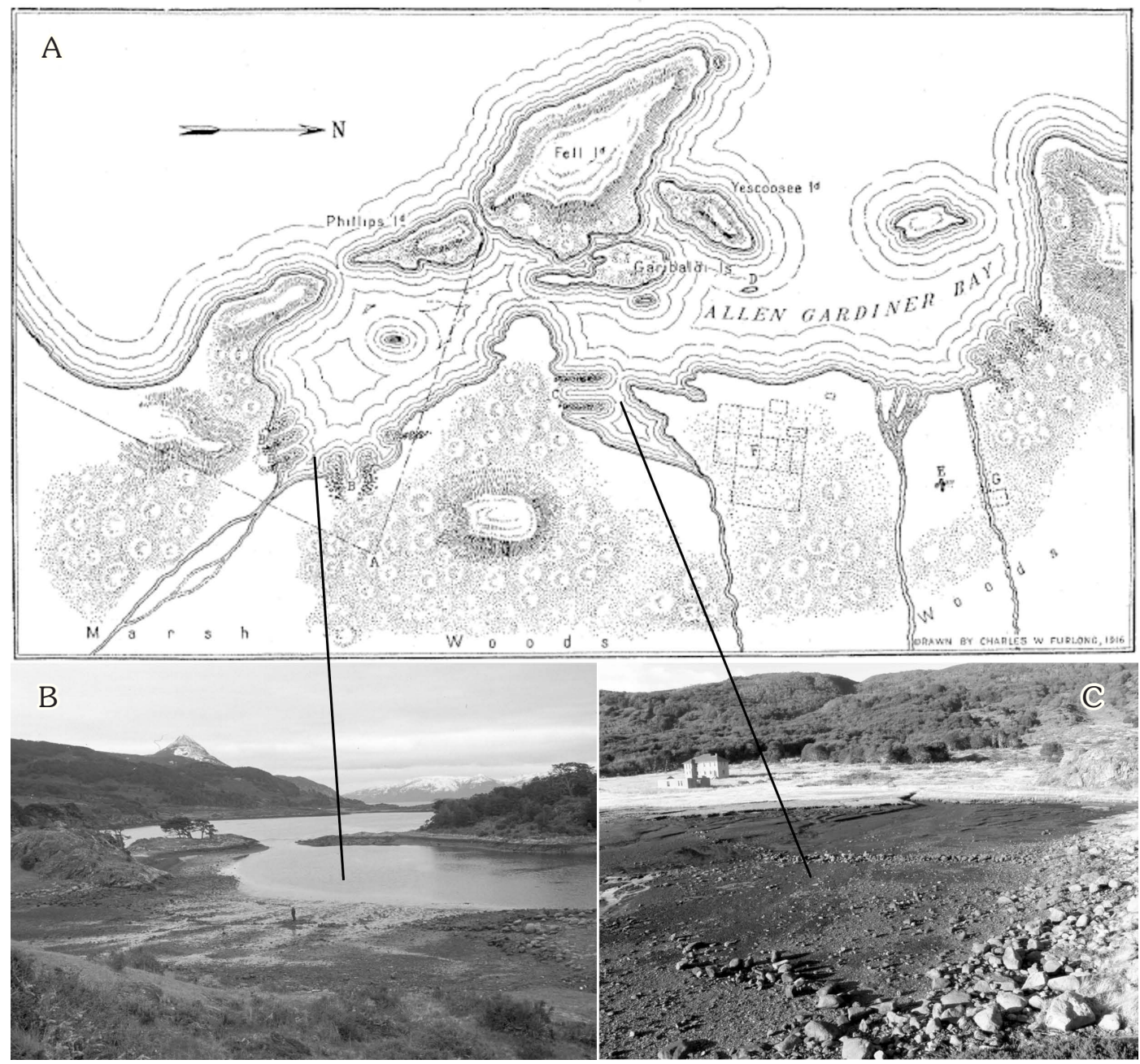

Fig. 1. Bahía Wulaia. A: plano esquemático de la bahía con la ubicación de las estructuras de pesca y los campos de chonchales (tomado de Furlong, 1917, p. 179). B: corrales en bahía sur correspondientes a referencia B en Furlong (1917). C: corrales en el sector norte de la bahía correspondientes a referencia C en Furlong (1917) (fotos gentileza Sr. Denis Chevallay). 


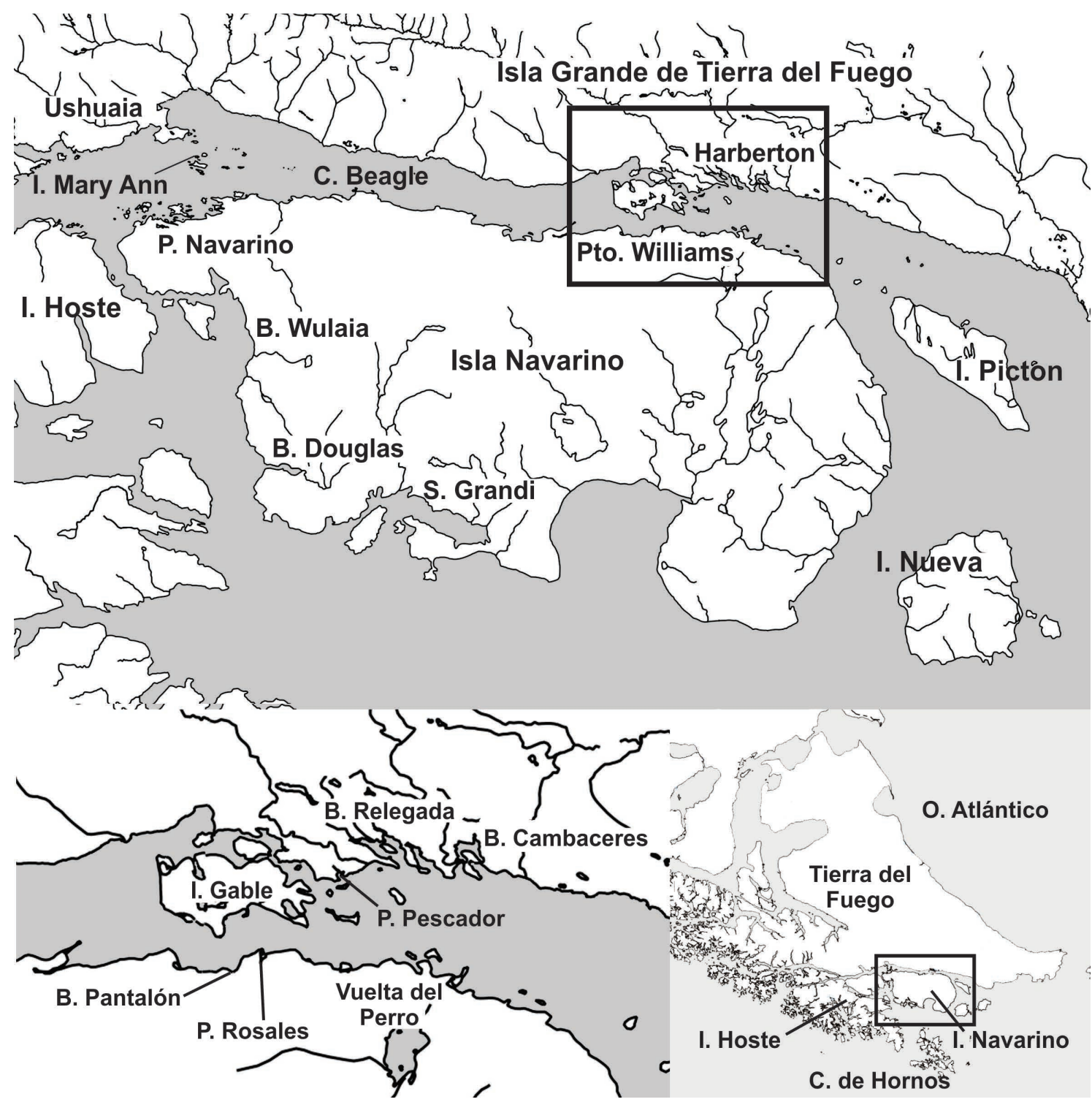

Fig. 2. Mapa de Ubicación, distribución de estructuras registradas en la región Canal Beagle - Isla Navarino y localidades mencionadas en el texto.

también Constantinescu 2005) (Fig. 1). También pueden citarse los casos de Punta Rosales y Vuelta del Perro -el primero registrado a partir de una fotografía en Massardo y Rozzi (2006, p. 133) y el

Tenemos conocimiento acerca de la existencia de otros dos casos en la costa sur de Navarino: uno en Bahía Douglas (Chevallay, com. pers. 2013) y otro en la costa norte del Seno Grandi (Álvarez, com. pers. 2013), otros cinco casos en el área costera al este de Puerto Navarino (Álvarez, com. pers. 2013; Chevallay, com. pers. 2013) y otro caso en la denominada bahía Pantalón, en costa norte segundo en una fotografía publicada por Álvarez y colaboradores (Álvares et al 2008, p. 109; Álvarez com. pers.)-, ambos ubicados en la costa norte de la isla Navarino ${ }^{2}$ (Fig. 2).

de isla Navarino (Piana, com. pers. 2015) (ver Fig. 2). En ningún caso disponemos de información detallada sobre sus características y esperamos que pronto puedan ser estudiados por los colegas chilenos, a quienes agradecemos mucho nos hayan permitido hacer referencia a esta información inédita. 
La pesca costera según la evidencia zooarqueológica

La evidencia arqueológica en la costa norte del canal Beagle permite señalar que este sector fue ocupado por sociedades con movilidad marítima y con una subsistencia fuertemente orientada hacia la explotación de recursos litorales desde aproximadamente los 6.400 años AP (Orquera \& Piana, 1999a, 2006). Los conjuntos zooarqueológicos de peces indican que estas sociedades consumieron una gran diversidad de especies ictícolas tanto de ámbitos costeros como pelágicos a lo largo de toda la secuencia ocupacional. Entre los taxones costeros predominan especies correspondientes a la familia Nototheniidae. En la Tabla 1 se presentan los NISP y sus proporciones en distintos sitios de la costa norte del canal Beagle. Puede observarse que los nototénidos chicos (Paranotothenia magellanica, Patagonotothen sp. y Nototheniidae sp.) alcanzan el $90 \%$ de los peces costeros explotados en toda

Tabla 1. Abundancia taxonómica (NISP) de restos ictiofaunisticos para conjuntos de la costa norte del canal Beagle (datos tomados de Zangrando, 2009a).

\begin{tabular}{|c|c|c|c|c|c|c|c|c|}
\hline Taxones & 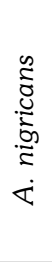 & 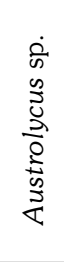 & 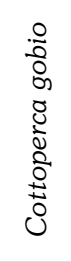 & 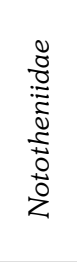 & 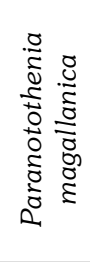 & 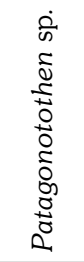 & 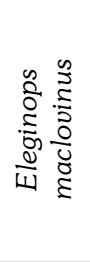 & $\begin{array}{l}\frac{\mathscr{O}}{\pi} \\
\frac{\pi}{0} \\
\ominus\end{array}$ \\
\hline $\begin{array}{l}\text { Túnel } 1\left(2^{\mathrm{do}} \text { Componente) }\right. \\
6400-4500 \text { años AP }\end{array}$ & 0 & 23 & 9 & 236 & 1196 & 349 & 15 & 1828 \\
\hline $\begin{array}{l}\text { Imiwaia } 1 \text { (Capas K, L y M) } \\
5900 \text { - } 4900 \text { años AP }\end{array}$ & 0 & 20 & 182 & 413 & 1701 & 67 & 364 & 2747 \\
\hline $\begin{array}{c}\text { Mischiuen I (Capa F) } \\
4890+210-4430+130 \text { años AP }\end{array}$ & 0 & 3 & 5 & 0 & 0 & 0 & 0 & 8 \\
\hline $\begin{array}{l}\text { Túnel } 1 \text { ( } 3^{\text {er }} \text { Componente) } \\
4300 \pm 80 \text { años AP }\end{array}$ & 0 & 1 & 0 & 2 & 0 & 3 & 0 & 6 \\
\hline $\begin{array}{l}\text { Imiwaia I (Capa D) } \\
3300 \text { años años AP }\end{array}$ & 0 & 0 & 0 & 0 & 5 & 13 & 1 & 19 \\
\hline $\begin{array}{c}\text { Túnel l ( } 4^{\text {to }} \text { Componente) } \\
2690 \pm 80-2660 \pm 100 \text { años AP }\end{array}$ & 0 & 1 & 0 & 0 & 9 & 3 & 0 & 13 \\
\hline $\begin{array}{l}\text { Túnel l ( } 5^{\text {to }} \text { Componente) } \\
1920 \pm 80 \text { años AP }\end{array}$ & 0 & 7 & 0 & 1 & 2 & 3 & 0 & 13 \\
\hline $\begin{array}{c}\text { Shamakush I } \\
1120 \pm 100-940 \pm 110 \text { años AP }\end{array}$ & 0 & 19 & 3 & 38 & 1022 & 603 & 1 & 1686 \\
\hline $\begin{array}{l}\text { Túnel I (6to. Componente) } \\
670 \pm 80-450 \pm 60 \text { años AP }\end{array}$ & 0 & 3 & 0 & 34 & 91 & 102 & 0 & 230 \\
\hline $\begin{array}{c}\text { Shamakush X } \\
500 \pm 100 \text { años AP }\end{array}$ & 0 & 29 & 11 & 7 & 191 & 11 & 0 & 249 \\
\hline $\begin{array}{l}\text { Imiwaia I (Capa B) } \\
150+70 \text { años AP }\end{array}$ & 1 & 8 & 0 & 6 & 149 & 25 & 1 & 190 \\
\hline $\begin{array}{l}\text { Lanashuaia I Siglo } \\
\quad \text { XIX AD }\end{array}$ & 0 & 0 & 0 & 39 & 32 & 4 & 1 & 76 \\
\hline Totales & 1 & 114 & 210 & 776 & 4398 & 1183 & 383 & 7065 \\
\hline$\%$ & 0 & 1,6 & 3 & 11 & 62,3 & 16,7 & 5,4 & 100 \\
\hline
\end{tabular}


la secuencia arqueológica de la costa norte del canal Beagle. Mientras que la representación de róbalo (Eleginops maclovinus) es muy baja y la de pejerrey (Odontesthes sp.) es prácticamente nula. Los róbalos tuvieron una importancia algo mayor en los conjuntos tempranos de Imiwaia I.

Recientes trabajos postulan la existencia de un proceso de intensificación -expresado por el sustancial aumento de especies de bajo rendimiento relativo, como peces y aves, en los conjuntos faunísticoshacia los últimos 1500 años de la secuencia (Tivoli \& Zangrando, 2011). La información derivada de los conjuntos ictiarqueológicos, ha sido analizada desde una perspectiva temporal y ecológica por Zangrando (2003, 2009a y b), destacándose un incremento en la frecuencia de especímenes de peces en los conjuntos datados entre los siglos XVI y XIX AD, expresado particularmente en la representación de nototénidos chicos (Paranotothenia magellanica y Patagonotothen sp.; Zangrando, 2009a, p. 254), lo cual sumado a las menores representaciones de pinnípedos y guanacos permite defender que la pesca ocupó un rol importante en la subsistencia canoera en estos tiempos. Este ascenso de las frecuencias de restos de peces costeros implicó, a su vez, un aumento en la inversión laboral en las actividades vinculadas a la obtención y el procesamiento de especies de menor rendimiento.

Llama la atención que el proceso de intensificación se haya focalizado en nototénidos chicos, mientras que el róbalo esté representado desde un comienzo por escasos especímenes. Las razones por las que este rasgo del registro es llamativo se deben a que ésta es la especie de mayor biomasa del canal Beagle (Lloris \& Rucabado, 1991; Lopez et al. 1996) ya que está disponible todo el año, por lo cual su ausencia no puede explicarse por variaciones estacionales. Por otro lado, el róbalo presenta la tasa de rendimiento más elevada entre los nototénidos, ya que supera ampliamente en talla y peso a $P$. magellanica y a las distintas especies del género Patagonotothen. Además, estudios previos no permiten defender causas tafonómicas o postdepositacionales para esta ausencia (Zangrando, 2003, 2007, 2009a). Esto llevó a Fiore y Zangrando (2006) a interpretar este caso como una posible consecuencia de pautas sociales de restricción, prohibición o evitación en el consumo de este recurso. Dado que los róbalos eran representados como espíritus en las ceremonias de iniciación en la sociedad Yámana, la interpretación sobre la evitación del róbalo parece estar reforzada por prescripciones probablemente implícitas en la esfera ideológica de dichas sociedades cazadorasrecolectoras de tiempos etnográficos en la región (Fiore \& Zangrando, 2006).

\section{LOS CORRALES DE PESCA EN LA COSTA NORTE DEL CANAL BEAGLE}

El primer dato sobre la existencia de un posible corral de pesca en cercanías de la desembocadura del río Lasifashaj (Puerto Pescador) nos fue informado en 2005 por el Sr. Adrián Roca, vecino de la ciudad de Ushuaia, quien había observado unos alineamientos de rocas bajo el agua en una pequeña ensenada. Posteriormente el sitio fue visitado por los autores comprobando la existencia de dos estructuras lineales y paralelas de bloques de roca. En esta ocasión se verificó que dichas estructuras se encontraban emplazadas en el sector intermareal, siendo totalmente cubiertas por la pleamar y quedando expuestas con la bajamar. La linealidad, el tamaño de los bloques que conforman ambas estructuras y su disposición en un sector del intermareal con una dinámica de muy baja energía nos indicaron su origen antrópico. Por otra parte, fueron detectados numerosos concheros en las inmediaciones, algunos de considerable tamaño.

El hallazgo de este rasgo, sumado a las particularidades del paisaje local, estimuló la prospección de otras localidades en las cercanías con configuraciones topográficas similares. A partir de una serie de expectativas generadas por las condiciones del emplazamiento de este primer caso y de la información etnográfica disponible, se determinaron rasgos ambientales que consideramos relevantes, a saber: relación con cursos de agua dulce, bahías o ensenadas internas, baja dinámica de mareas, fondos fangosos, relación de altura con los niveles de máxima marea y cercanía a yacimientos arqueológicos conocidos. Luego de analizar configuraciones del paisaje donde se conjugaban estas características en distinto grado, se seleccionaron seis localidades a relevar con 
marea baja, que se sumarían al caso donde ya había sido identificada la estructura de Puerto Pescador. Los lugares determinados fueron: Paso Guaraní, Bahía Relegada Sur, Relegada Centro, Relegada Norte, bahía Harberton y bahía Cambaceres interior (Fig. 2). Estas prospecciones dieron como resultado el hallazgo de otras estructuras de rocas en el intermareal, además de la identificada inicialmente.

Las localidades mencionadas se encuentran en la zona de Ea. Harberton, en el sector oriental del canal Beagle. Esta zona se caracteriza por la presencia de depósitos glaciarios y la alternancia de playas extensas y profundas bahías, el rasgo más destacable de esta área es la existencia de un extenso campo de drumnlis entre bahía Brown y estancia Harberton en la costa norte del canal, y la zona de Puerto Williams en la margen sur (Fig. 2) (Rabassa et al. 1990; Rabassa et al. 2000. pp. 223-224). Estas geoformas generan un paisaje con una línea de costa muy irregular, con profundas bahías, caletas protegidas e islas, por ejemplo: bahías Cambaceres, Harberton, Relegada y Brown o las islas Gable, Warú, Martillo y Yunque. Este tipo de configuración ambiental resulta en un paisaje litoral con características diferenciales y específicas frente a otros tipos de costas en el canal Beagle. Estas bahías cerradas y caletas de escasa profundidad, con fondos planos y fangosos, constituyen ámbitos donde la acción de las corrientes marinas es débil y el oleaje es poco importante. A su vez las escasas pendientes de estas costas generan extensas zonas intermareales que durante la pleamar son ocupadas por peces que habitan en ámbitos mixohalinos como róbalos y pejerreyes, por lo que resultan espacios óptimos para la captura de estos recursos.

Más recientemente, el Sr. Pablo Smiht, también vecino de la ciudad de Ushuaia, informó sobre la presencia de otra alineación de rocas ubicada en un sector intermareal de la Isla Mary Ann (islas Bridges) frente a la bahía de Ushuaia, la cual también fue identificada por los autores de este trabajo como una estructura de origen antrópico. Si bien las islas Bridges conforman una zona con una configuración ambiental distinta a la zona de Ea. Harberton las condiciones locales asociadas al emplazamiento del corral presentan rasgos comunes.

\section{Puerto Pescador}

Aproximadamente un kilómetro hacia oeste de la desembocadura del río Lasifashaj se emplaza una bahía muy protegida por afloramientos rocosos denominada localmente Puerto Pescador (Fig. 2). Dentro de esta bahía, en su margen este, se abre una pequeña ensenada en la cual se hallaron dos estructuras de rocas. Se trata de dos alineaciones paralelas construidas con bloques que cierran la entrada de esta ensenada interior. El cuerpo de agua cercado durante las mareas altas es de aproximadamente $6.000 \mathrm{~m}^{2}$. La estructura externa, más próxima al mar, tiene aproximadamente $26 \mathrm{~m}$ de largo, con una abertura de unos 3,7 m en el centro, su ancho es irregular -oscilando entre 1 y 1,5 m aproximadamente- y los bloques de mayor tamaño tienen un promedio de $55 \times 30 \mathrm{~cm}$, habiéndose registrado dimensiones de hasta $116 \mathrm{~cm}$ de largo máximo. Esta estructura tiene una profundidad máxima de $96 \mathrm{~cm}$ con respecto al nivel de la pleamar disminuyendo hacia ambos extremos hasta una profundidad de 40 $\mathrm{cm}$ aproximadamente. La estructura interna (más lejana del mar) se dispone $13 \mathrm{~m}$ hacia el interior de la ensenada, respecto de la estructura externa. Mide 23 metros de largo, es de menor espesor y a diferencia de la estructura externa la parte central no presenta abertura.

Los bloques utilizados en ambos casos son coincidentes con el tipo y el tamaño de rocas disponibles en las inmediaciones. Se trata de alineaciones de bloques de mayor tamaño que los presentes en el fondo de la ensenada, pero en ninguna de las estructuras estos bloques se encuentran apilados o encastradas a la manera de una pirca o "muralla" (Figs. 3 y 4). La estructura externa está construida con una mayor cantidad de bloques y el tamaño promedio de las rocas es superior a los utilizados en la construcción del dique interno, lo que resulta en una apariencia mejor definida. Hacia el centro de esta estructura se verificó la mayor abundancia de bloques y la presencia de los tamaños más grandes. Asimismo, a ambos lados de esta abertura se observó que el alineamiento de rocas presenta una leve inflexión hacia el exterior de la bahía.

En esta localidad se detectó la presencia de numerosos sitios arqueológicos-todos ellos concheros- 


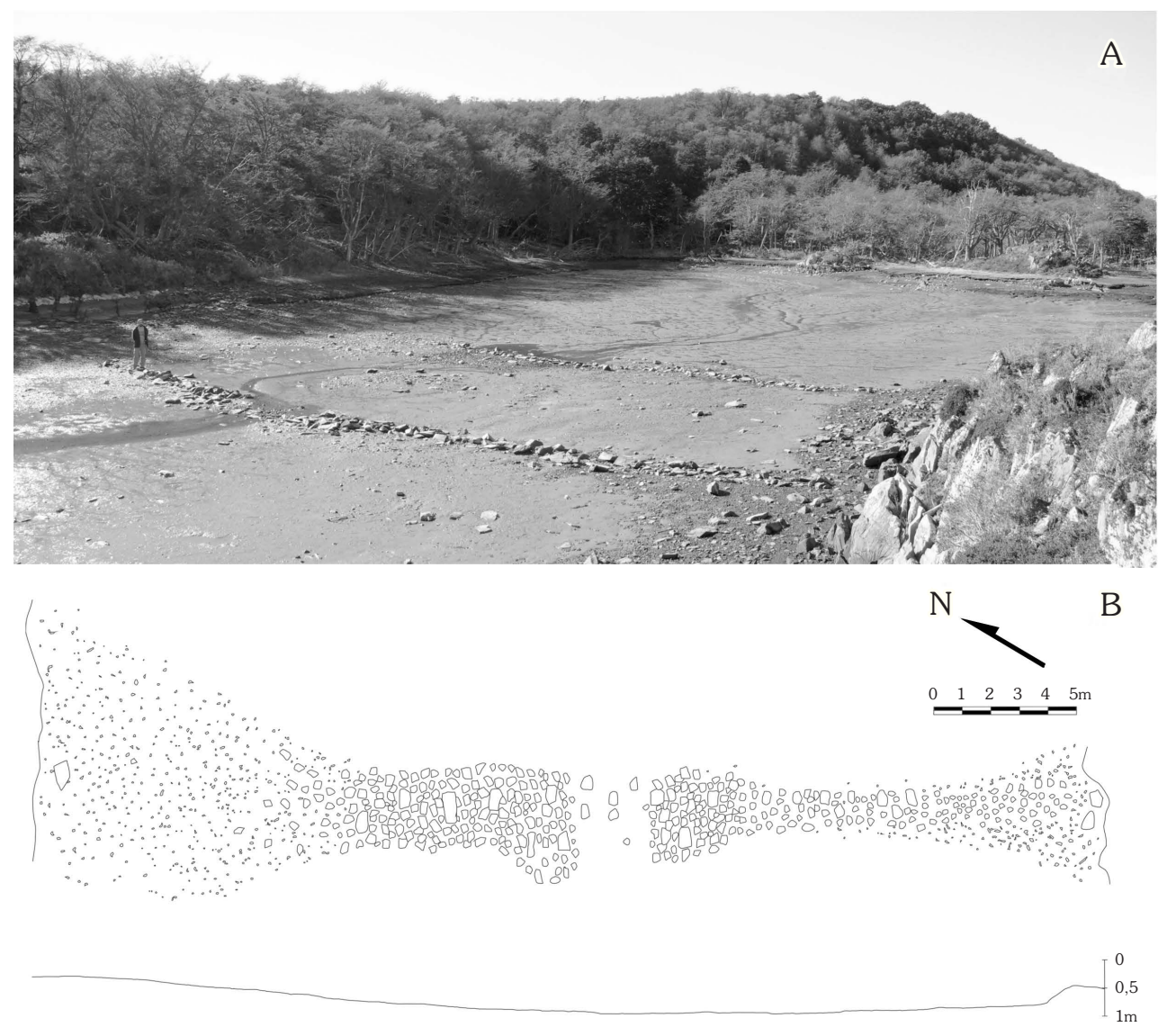

Fig. 3. Localidad Puerto Pescador. A: vista general del emplazamiento tomada desde lado sur de la ensenada. B: plano de la estructura externa.

de diferentes dimensiones, el más inmediato a las estructuras presenta al menos tres estructuras anulares (sensu Orquera \& Piana, 1992) de gran potencia, alineadas sobre la margen norte de la ensenada. En la costa oeste de la bahía se determinó la presencia de un yacimiento de importantes dimensiones, incluyendo una agrupación de numerosas estructuras anulares y domos (sensu Orquera \& Piana, 1992) de gran potencia que se extiende en una superficie de más de $4.500 \mathrm{~m}^{2}$. Además se registraron otros emplazamientos -11 en total- de tamaño mediano y chico dispersos por la zona en un radio no mayor a $500 \mathrm{~m}$.

\section{Bahía Relegada}

Bahía Relegada es una amplia y protegida entrada de mar, rodeada por drumlins, que penetra más de dos kilómetros hacia el interior.
Se divide en dos brazos conectados por un canal que se inunda sólo durante la pleamar y en sus cabeceras desembocan tres arroyos, formando estuarios angostos y profundos que son inundados diariamente por las mareas (Fig. 2). Fueron prospectadas las tres desembocaduras y se hallaron estructuras en dos de ellas, la central y la norte.

\section{Bahía Relegada Centro}

El estuario central tiene un largo aproximado de 800 m, su mitad distal presenta un área de planicie atravesada por un canal de marea y la sección proximal o externa un área de marisma más abierta $e$ inundable. Las tres estructuras registradas en esta localidad se emplazan en un mismo sector del canal de mareas, a pocos metros de su desembocadura en la marisma (Fig. 5). Se trata de un dique principal, de posición central en relación con las otras dos 


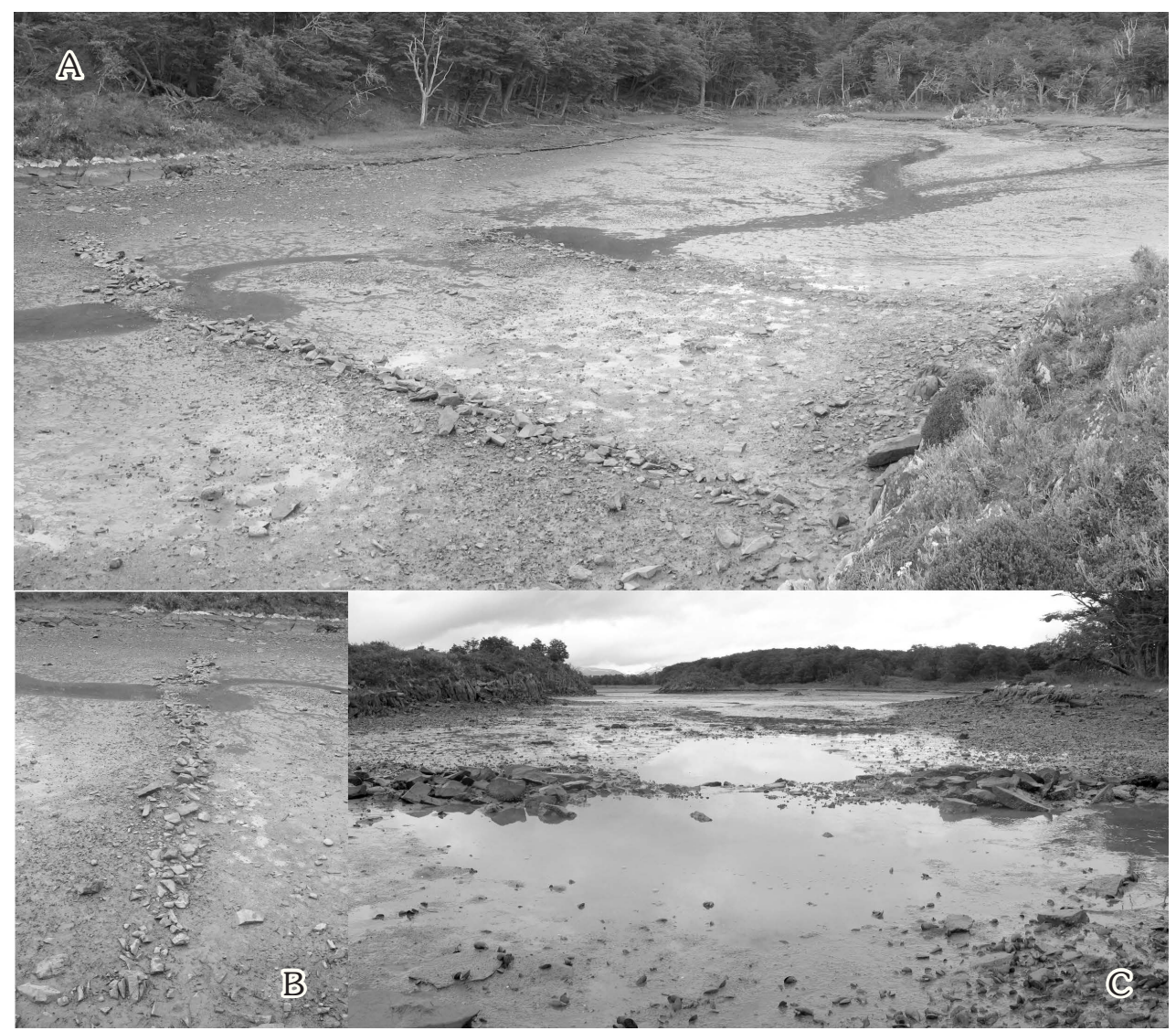

Fig. 4. Localidad Puerto Pescador. A: vista general de las estructuras. B: detalle constructivo de la estructura externa. C: detalle de la abertura ubicada en el centro de la estructura externa, vista desde el interior de la ensenada. Todas las fotografías fueron tomadas con mareas bajas.

agrupaciones lineales de bloques que podrían corresponder a estructuras secundarias o bien menos preservadas. Estas estructuras se disponen de forma subparalela entre si y en forma perpendicular a la dirección de la corriente, bloqueando el canal de mareas de unos $10 \mathrm{~m}$ de ancho promedio. Están conformadas por bloques redondeados, la estructura central presenta bloques de unos 39,1 x 27,7 cm de tamaño promedio, habiendo registrado tamaños máximos de hasta $60 \times 36 \mathrm{~cm}$. Todas las estructuras se encuentran parcialmente sumergidas, incluso con las más bajas mareas, debido a la corriente de desagüe del arroyo, lo que dificulta la visibilidad de la estructuras completas. El dique principal, tiene unos nueve metros de largo y presenta una discontinuidad en su extremo norte, aunque es difícil discernir si corresponde a algún tipo de abertura intencional o a un sector donde la corriente hubiera desmoronado la estructura original. Por su parte las estructuras emplazadas en posición externa e interna con relación a la estructura central tienen un largo estimado de ocho y siete metros erespectivamente.

$\mathrm{Si}$ bien no se observaron sitios en las adyacencias de las estructuras descriptas, se detectó un conchal de grandes dimensiones $\left(\sim 5.000 \mathrm{~m}^{2}\right)$ al otro lado de la colina que forma la costa sur del brazo central de bahía Relegada, a 150 m en línea recta desde el emplazamiento de los corrales. Esta localización está compuesta por una gran cantidad de estructuras anulares y domos de considerable potencia.

\section{Bahía Relegada Norte}

Con una disposición paralela al estuario descripto y distante aproximadamente unos 500 $m$ en dirección noreste se encuentra otra entrada 


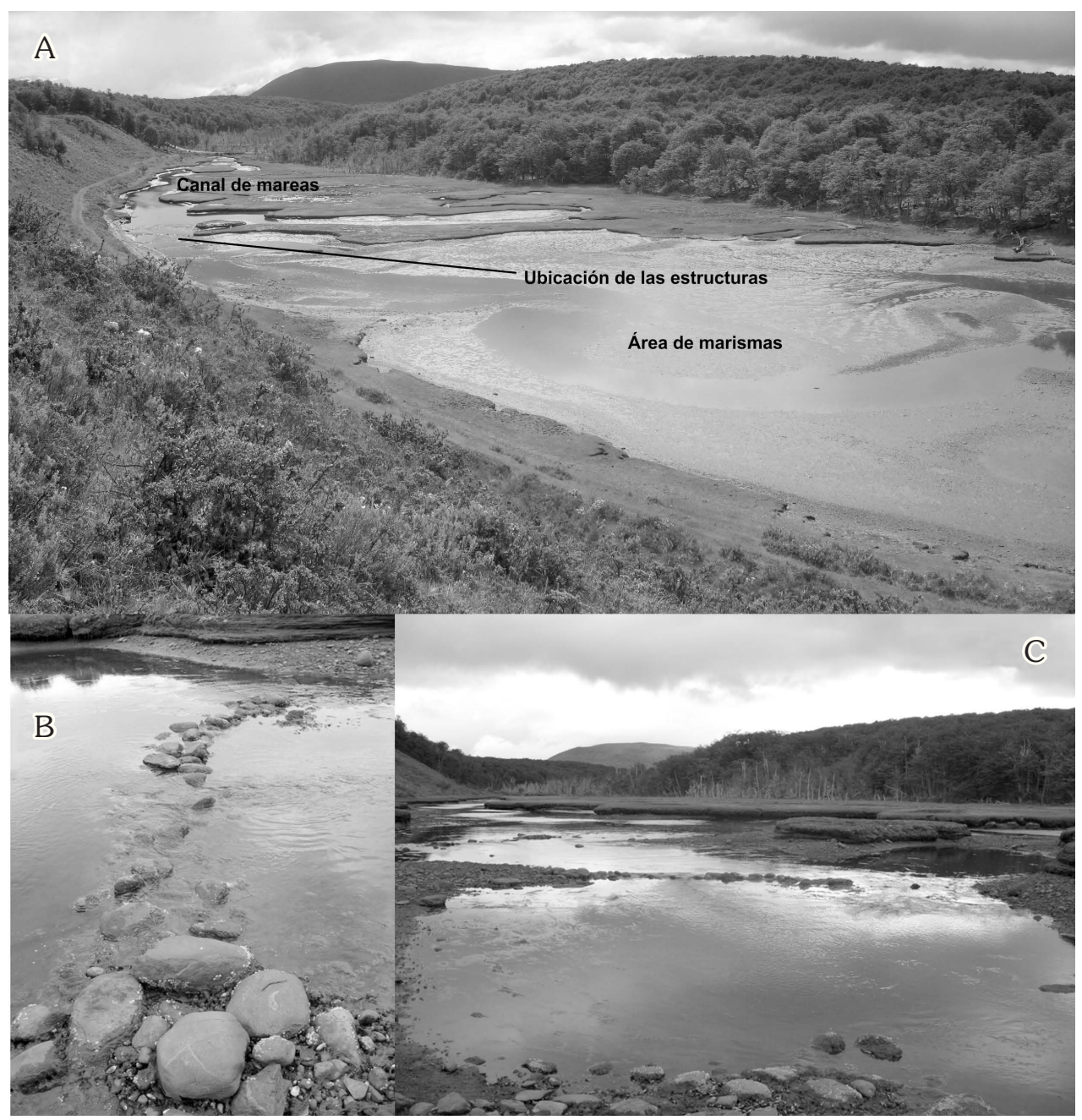

Fig. 5. Localidad Relegada Centro. A: vista del estuario y emplazamiento de los corrales de pesca.

B: detalle de la estructura principal. C: vista de la estructura principal, al fondo puede observase otra de las estructuras mencionadas. Todas las fotografías fueron tomadas con mareas medias.

de mar de similares características, aunque de menor extensión (550 m aproximadamente) y sin una distinción tan clara entre canales y planicies de mareas. En este sitio se han registrado dos estructuras de muy diferentes características, situadas en la parte central del estuario, en un sector de marisma inundable. La estructura interna, de mayores dimensiones, posee aproximadamente $25 \mathrm{~m}$ de largo y un ancho de unos 3,50 m, está conformada por guijarros y grava y presenta una abertura central de aproximadamente tres metros (Fig. 6). La mayor profundidad se registra en esta abertura central alcanzando los $92 \mathrm{~cm}$ con respecto al nivel máximo de mareas y disminuyendo hacia ambos extremos de la estructura hasta una profundidad de 78-76 cm. Esta estructura está ubica sobre un nivel de sedimento fino de origen marino y de aproximadamente $50 \mathrm{~cm}$ de potencia, que sepulta a su vez a un nivel de turba. Esta observación y la ubicación en un sector interno del estuario de baja energía nos permiten descartar la posibilidad que se trate de un depósito natural (p.e. cordón litoral), lo que refuerza su origen cultural.

El cuerpo de agua cercado por esta estructura durante las mareas altas es de aproximadamente $8.000 \mathrm{~m}^{2}$. Unos $76 \mathrm{~m}$ hacia la boca de la caleta y obturando el canal de desagüe central del canal de mareas se registró un dique 
recto construido con guijarros grandes y bloques de unos $8 \mathrm{~m}$ de largo máximo, de indudable origen antrópico (Fig. 6).

\section{Bahía Cambaceres interior}

Cambaceres interior es una bahía amplia pero muy cerrada (Fig. 2). En su extremo norte se encuentra una ensenada de unos $200 \mathrm{~m}$ de largo, en cuya cabecera desemboca un pequeño drenaje de turba, donde pueden observarse dos alineaciones de guijarros en forma de arco. Se disponen en forma subpalela, la externa, mejor definida, presenta su concavidad hacia el interior de la ensenada y la interna su concavidad hacia el exterior de la ensenada, lo que genera un espacio intermedio de forma elíptica (Fig. 7). La alineación externa tiene unos $42 \mathrm{~m}$ de largo y su ancho varía entre los 6,60 y 5,20 m y la interna un largo de $32,30 \mathrm{~m}$ de largo y su ancho varía entre los 2,40 y $1,90 \mathrm{~m}$.

Las estructuras registradas en esta localidad son las menos definidas, en comparación con las descriptas previamente, lo que genera ciertas dudas sobre su interpretación como estructuras antrópicas. No obstante las características de su emplazamiento son similares a otros casos descriptos. En caso de tratarse de estructuras de origen antrópico, probablemente el uso de guijarros y gravas para su construcción genere una condición de menor obstrusividad que aquellas donde fueron utilizados bloques de mayor tamaño; o bien podría tratarse de estructuras en las cuales las condiciones de preservación no sean las mejores. En otras palabras, en este caso no es segura su adscripción a un corral de pesca y esperamos que futuros trabajos permitan avanzar en su definición, no obstante lo cual consideramos oportuna su mención en este trabajo.
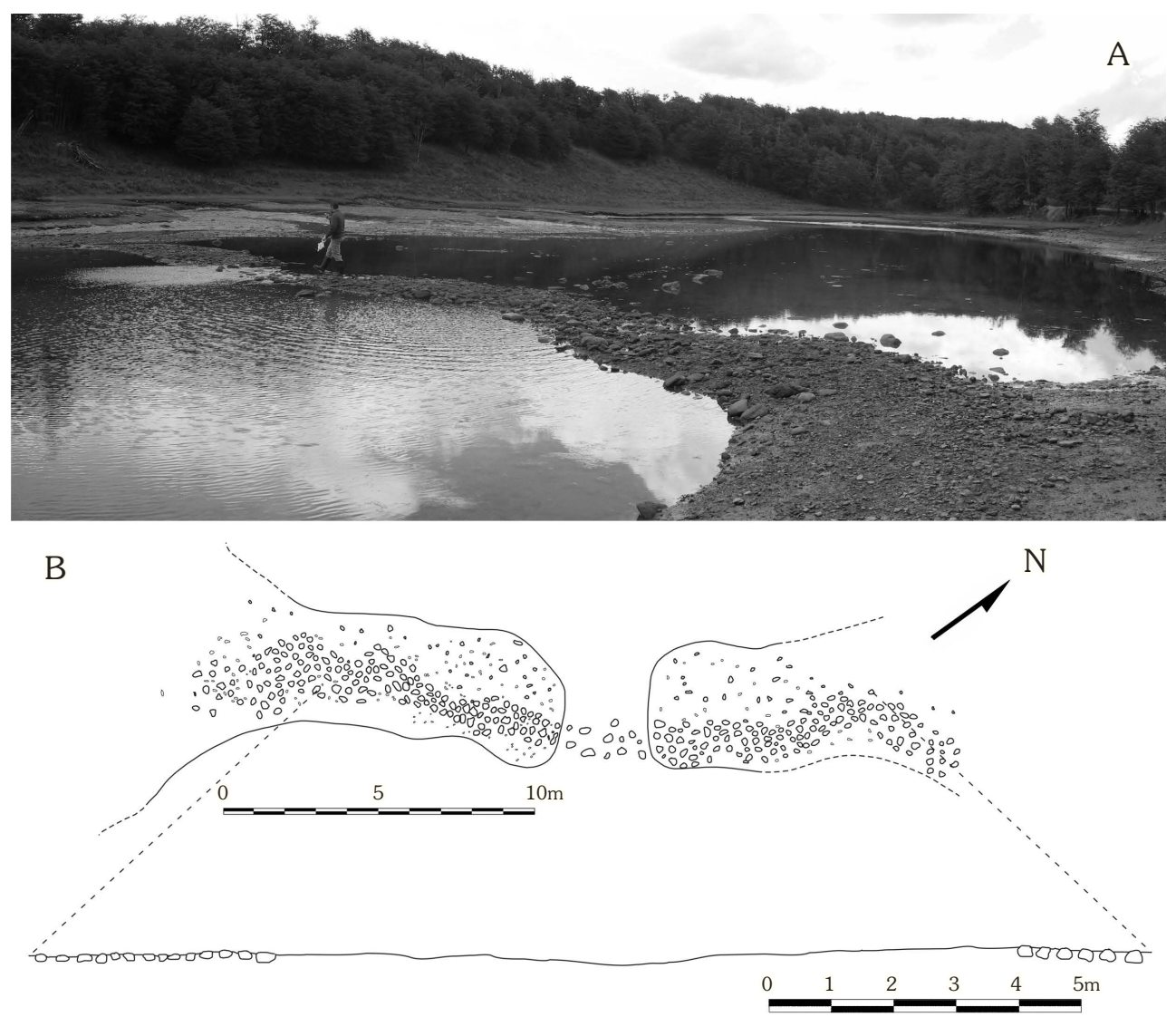

Fig. 6. Localidad Relegada Norte. A: estructura interna (principal), fotografía general del emplazamiento vista desde la margen norte (la fotografía fue tomada con marea media). B: plano de la estructura principal. 


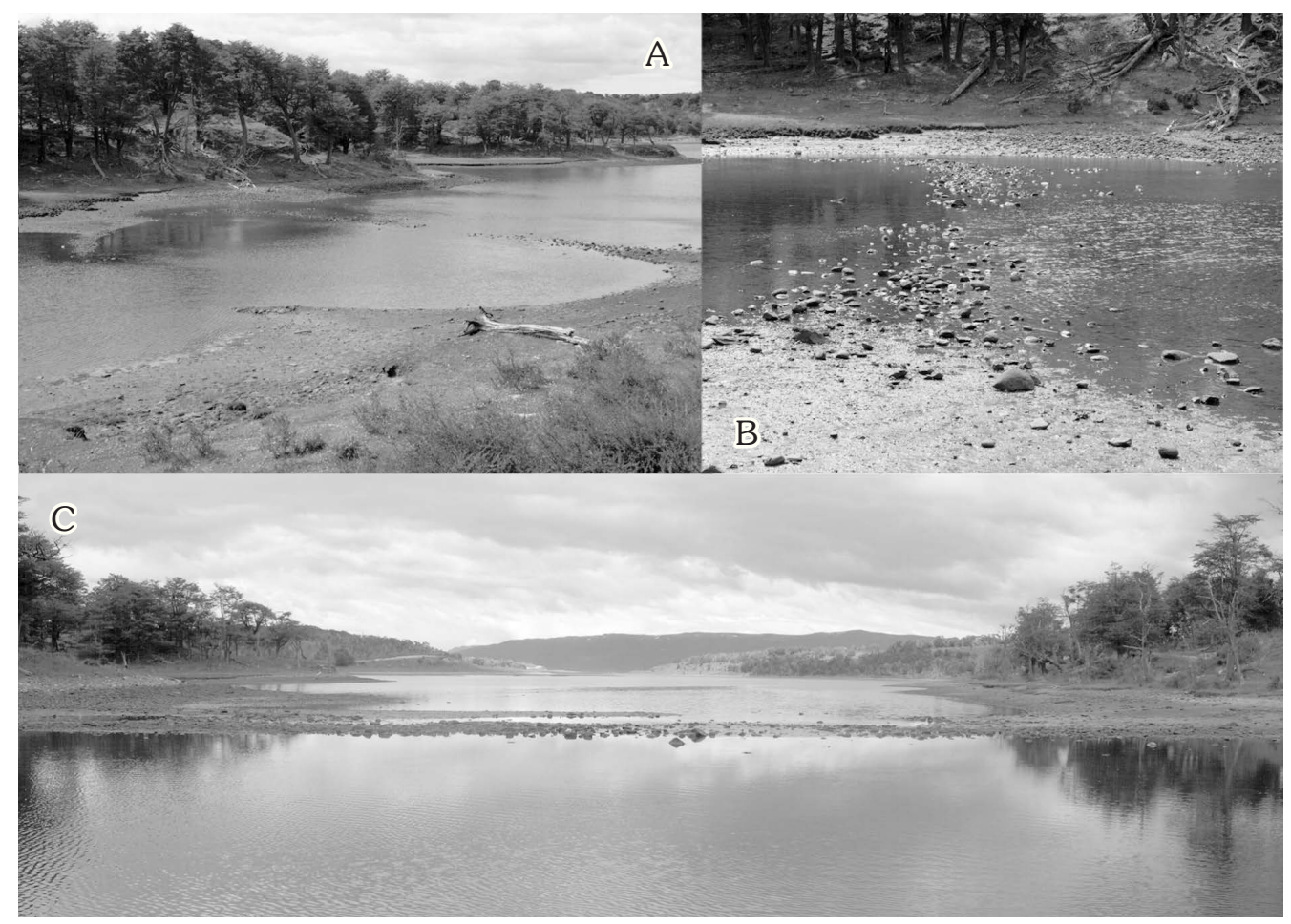

Fig. 7. Bahía Cambaceres interior. A: vista general del emplazamiento tomada desde margen este. B: detalle de estructura externa vista desde margen este. C: estructura externa vista desde el interior de la ensenada. Todas las fotografías fueron tomadas con mareas medias.

\section{Isla Mary Ann (Islas Bridges)}

A diferencia de los casos hasta aquí presentados la estructura de rocas registrada en la isla Mary Ann, frente a la bahía de Ushuaia (Fig. 2), presenta condiciones de emplazamiento diferentes. Este rasgo encierra un sector del intermareal que se extiende entre afloramientos de roca sobre el ángulo noroeste de dicha isla. Alli se observó una estructura lineal de bloques y rodados de nueve metros de largo por un ancho máximo de 2,5 m. Los tamaños de las rocas varían desde rodados del tamaño de un puño hasta bloques que alcanzan un metro de largo máximo (Fig. 8). La estructura apoya sobre un substrato arenoso en casi toda su extensión salvo en sus extremos donde descansa parcialmente sobre afloramientos de la Formación Yahgan (Caminos, 1980). La densidad de bloques y rodados disminuye significativamente en su parte central describiendo una apertura de cerca de dos metros de ancho. En este sector la estructura de rocas alcanza una profundidad de $117 \mathrm{~cm}$ por debajo del nivel máximo de mareas y disminuye su profundidad a unos $75 \mathrm{~cm}$ en promedio hacia ambos extremos. Esta estructura encierra un sector del intermareal con una superficie de aproximadamente $1.250 \mathrm{~m}^{2}$. Se observaron conchales a una corta distancia $(\sim 70$ $\mathrm{m})$ siguiendo la línea de costa hacia el Este.

\section{DISCUSIÓN}

\section{Emplazamiento y técnicas constructivas}

Desde una perspectiva comparativa, si bien cada uno de los casos identificados presenta sus particularidades, también es posible detectar ciertas pautas en la disposición de las estructuras en el intermareal, así como en algunas características morfológico-constructivas. $\mathrm{Si}$ analizamos en conjunto los casos presentados en este trabajo, se observa que el montaje de estas tecnologías de pesca siempre se da en espacios protegidos del intermareal, ya sea en el interior de caletas o estuarios, o al reparo de afloramientos rocosos. Estos espacios presentan condiciones de baja energía en 

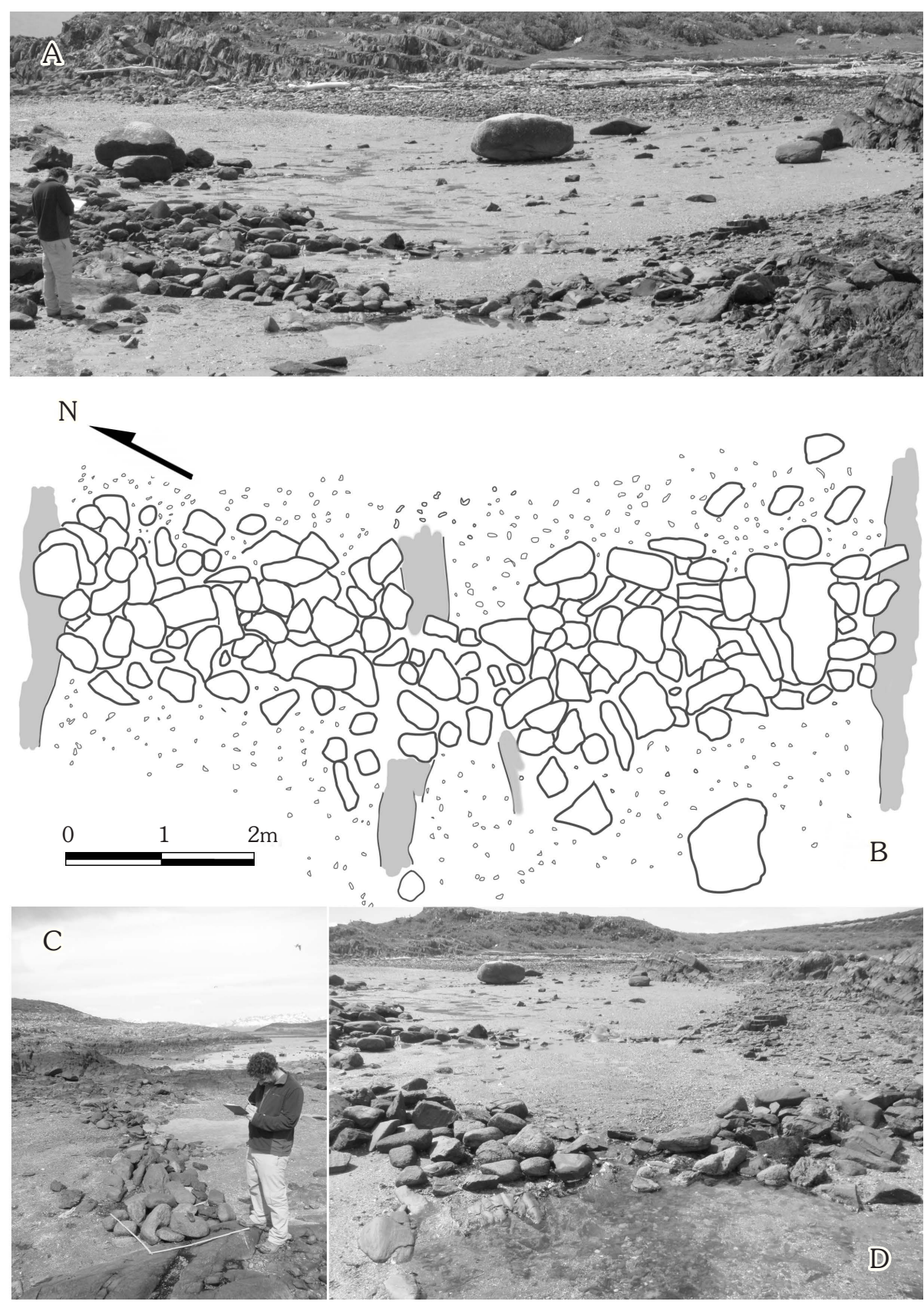

Fig. 8. Localidad Mary Ann. A: vista general de la estructura y el emplazamiento vista desde el oeste (fotografías tomadas con marea baja). B: plano de la estructura.

$\mathrm{C}$ y D: detalles constructivos de la parte norte y la abertura central respectivamente

el ciclo diario de mareas y poca exposición a las condiciones del oleaje que predominan en sectores abiertos de costa. Excepto el caso de la isla Mary Ann, se observa que las estructuras de roca están asociadas a desembocaduras de cursos de agua dulce de bajo caudal. Además, resulta evidente que estas estructuras se ubican siempre sobre substratos arenosos o barrosos a una profundidad de aproximadamente un metro por debajo del nivel máximo de mareas. Esto condice de manera muy 
ajustada con lo indicado por las fuentes escritas en cuanto a la forma constructiva de estas estructuras y que hemos mencionado previamente. Las aberturas centrales están claramente definidas en al menos tres casos (Puerto Pescador, Relegada Norte e isla Mary Ann), aunque la abertura también puede darse lateralmente si consideramos lo observado en Relegada Centro. Este aspecto constructivo también está mencionado en las fuentes escritas (ver arriba) y constituirian partes funcionales de los corrales de pesca.

La presencia de dos estructuras paralelas es indudable en el caso de Puerto Pescador. En otras localidades también se observó la presencia de posibles estructuras cercanas a las alineaciones de rocas principales, menos definidas o mal preservadas. Por el momento no nos es posible discernir si estas estructuras formaban parte de un mismo sistema de captura más complejo -a la manera de diques escalonados o delimitando espacios intermedios donde encerrar a los peces- $\mathrm{O}$ si bien corresponden a construcciones montadas en distintos momentos, donde se habría dado la reutilización de bloques o rodados de estructuras inactivas. Cabe también la mención sobre la similar conformación de estructuras paralelas visible en el caso de bahía Wulaia (ver Fig. 1) y otros casos mencionados para isla Navarino.

En todos los casos se utilizaron el tipo de bloques, rocas o guijarros disponibles en las inmediaciones. Por lo tanto, la amplitud del espectro de variación entre "murallas de piedra" y "garrotes cortos hundidos en la tierra", que se desprende de las descripciones de Bridges y Gusinde respectivamente, podría deberse a cuestiones situacionales relacionadas con la disponibilidad de distintos tipos y tamaños de rocas, así como a costos diferenciales de construcción. Esta variabilidad en el tipo de materiales utilizados generaría una consecuente variabilidad en las condiciones de obstrusividad y del potencial de preservación de estas estructuras. Continuando con este razonamiento, es esperable que hubiesen existido condiciones en las cuales frente a la baja oferta de rocas grandes se construyeran corrales de ramas con bases de guijarros pequeños, lo que implicaría mayores dificultades para su detección; el caso de bahía Cambaceres interior podría reflejar esta posibilidad, aunque como fue mencionado, consideramos que su asignación cultural aún no es segura.

\section{¿Una tecnología de pesca}

tardía en el canal Beagle?

A partir de la información etnográfica disponible para la región del canal Beagle, no parece desprenderse que los corrales de pesca o tecnologías similares hubiesen sido de uso frecuente por los yámanas. Si bien Gusinde y Bridges coinciden en la descripción de su funcionamiento $y$ en particularidades sobre el emplazamiento o caracteres constructivos, a excepción de la referencia de Furlong, en ningún caso se menciona la observación de estas estructuras ya sea en funcionamiento o en desuso. Por otra parte hasta el momento tampoco abundaban los casos arqueológicos, sin embargo algunas referencias relativamente recientes junto a los casos presentados en este trabajo parecen estar invirtiendo la situación. Hasta el momento podemos contabilizar al menos cuatro localidades con estructuras de pesca en la costa sur de Tierra del Fuego y alrededor de ocho en Isla Navarino; cantidad que podría incrementarse en la medida que se extiendan las prospecciones a otros sectores y se profundicen los trabajos en las áreas ya relevadas. Es posible que la baja frecuencia de hallazgos de estructuras de este tipo reportada hasta el momento se explique en parte por cuestiones de muestreo, ya que si bien en la costa norte del Beagle se han realizado prospecciones intensivas, estas no han incluido la exploración sistemática del espacio intermareal, por lo cual estas estructuras podrían haber pasado desapercibidas. Por otra parte, aún quedan amplísimos espacios del canal Beagle y regiones aledañas donde podrían ser halladas evidencias de artes de pesca de esta naturaleza.

En los casos aquí descriptos no se registraron restos de estacas enterradas asociadas a las estructuras de piedra susceptibles de ser fechadas. Tampoco es posible vincularlos con los sitios cercanos debido a que por el momento estos yacimientos no han sido objeto de excavaciones o sondeos. Por lo tanto, la asignación temporal de estas estructuras sólo puede ser estimada en términos tentativos y considerando el ascenso relativo del nivel de mar en las costas del canal 
Beagle (Rabassa et al. 2000; Coronato et al. 1999a; Gordillo et al. 1992). Hacia inicios del Holoceno medio -luego de alcanzado el máximo nivel transgresivo como consecuencia del ascenso de los niveles marinos registrado a escala macroregional- se produce una regresión paulatina de los niveles costa, producto de la combinación de fenómenos glacioeustaticos y tectónicos (Rabassa et al. 2000; Coronato et al. 1999a; Gordillo et al. 1992). Este proceso no fue constante durante momentos posteriores del Holoceno, habiéndose registrado evidencias de un incremento en el ritmo de elevación para los últimos 1.000 años (Gordillo et al. 1992). Por otra parte, este proceso tampoco fue uniforme a lo largo de la costa norte del Beagle, ya que en algunos sectores como hacia el este del rio Lasifashaj el ritmo de elevación habría sido considerablemente más lento (Coronato et al. 1999b). Si bien los ritmos de ascenso glacioeustatico difirieron espacial y temporalmente, es defendible que estas estructuras sólo podrían haber sido funcionales en tiempos relativamente recientes, dado que se localizan en espacios intermareales actuales. Sin embargo, tampoco es posible descartar que al menos alguno de los casos aquí mencionados esté relacionado con inmigrantes de origen Chilota-Hulliche arribados a la región en tiempos modernos (Skewes et al. 2012), aunque las estructuras aquí descriptas tienen estilos constructivamente diferentes a los registrados en Chiloé (Álvarez et al. 2008). Tampoco se conoce que esta práctica de pesca haya sido habitual entre los peones de campo que trabajaron en la Estancia Harberton (Natalie Goodall, com. pers. 2013).

La amplia dispersión de estas artes de pesca a lo largo de todo el litoral pacífico del centro y sur de la Patagonia, llevó a Álvarez y colaboradores (2008) a plantear la existencia de una co-tradición forjada en el contexto de alta movilidad y asiduos contactos característicos de las culturas canoeras. Aunque los diques hallados en el canal Beagle se diferencian en algunos aspectos de los corrales de pesca identificados para el área de Archipiélago de Chiloé (Alvarez et al 2008) e incluso a los descriptos para bahía Inutil, dentro del ámbito fueguino (Torres, 2009), los principios básicos de funcionamiento y construcción son los mismos. Sin embargo, debemos destacar algunas diferencias que podrían constituirse en singularidades de los casos del Beagle. Por un lado en la región de Chiloé, $e$ incluso en los casos descriptos para la zona de Bahía Inútil la gran mayoría de los corrales han sido identificados en playas abiertas. En general los corrales corresponden a estructuras o complejos de estructuras en forma de un "arco abierto hacia tierra firme" o bien de morfología circular, elíptica o rectangular, la extensión de estos complejos pueden superar hasta los $500 \mathrm{~m}$ a lo largo de la línea de costa y las dimensiones promedio de los corrales individuales son de 43,25 x 24,70 m (Alvarez et al. 2008, pp. 120-121). También, aunque en menor medida, se menciona la preferencia para el emplazamiento de corrales de varas y ramas en desembocaduras y ambientes estuarinos, asociados a fuentes de agua dulce (p. 118) y cabe destacar la observación sobre la existencia de "corrales de pesca de muros lineales, como obstrucciones transversales en cursos de agua, además de las estructuras en forma de arco" (p. 121), estos últimos registrados en territorios Kaweskar.

Los casosemplazadosen el Beagle no parecen ceñirse a una tipología constructiva definida, más bien esta se adapta a las condiciones y a la oferta de materiales de cada lugar. Las estructuras aquí descriptas y aquellas que pudieron ser visualizadas mediante las fotografías parecen ajustarse a las modalidades constructivas de "corrales simples", ya sean con muros de guijarros/clastos o bloques, propuestas por Álvarez et al. (2008, p. 117).

El modelo de intensificación de las actividades de pesca, con la incorporación de tecnologías pesqueras con mayor nivel de inversión laboral para los últimos siglos de la secuencia del canal Beagle, propuesto por Zangrando (2009a y b), constituye un contexto social y económico adecuado para la incorporación de estrategias de captura como los corrales de pesca; aunque esto no descarta que este tipo de tecnología haya sido utilizado desde momentos más tempranos. Resulta difícil, sin embargo, relacionar esta tecnología al modelo de intensificación señalado ya que se esperaría un aumento considerable de especies de peces característicos de ámbitos mixohalinos, como son róbalos y pejerreyes, en el registro ictioarqueológico regional. Esta expectativa no sólo se desprende del contexto costero y microambiental donde se encuentran emplazadas estas estructuras sino por lo registrado en la información etnográfica. 
El punto es que el proceso de intensificación quedó documentado a partir del aumento significativo de nototénidos chicos, mientras que en los conjuntos tardíos estudiados se han identificado muy escasos restos de róbalos y de pejerreyes. No obstante, esto no descarta la posibilidad que los restos de róbalos y pejerreyes estén presentes en sitios arqueológicos con emplazamientos particulares (como podría ser en el interior de ensenadas o estuarios) y que por esa razón aún no hayan sido registrados en los conjuntos zooarqueológicos estudiados.

\section{CONSIDERACIONES FINALES}

La existencia de estructuras de captura masiva de peces en la región del canal Beagle era conocida a partir de las fuentes etnográficas, sin embargo, hasta el momento, la carencia de precisiones sobre su ubicación y características limitaba cualquier discusión al respecto. En este aspecto radica lo novedoso de este trabajo aportando un primer registro material de esta tecnología de pesca. Sería interesante ampliar el rango geográfico de prospecciones que tengan como objetivo la documentación de estructuras de este tipo y efectuar excavaciones o muestreos en los yacimientos cercanos a los casos detectados para contextualizar estos hallazgos en una discusión de mayor espectro.

Otra discusión que puede derivarse de la presencia de estos rasgos, está relacionada con las implicancias sociales de estas técnicas de captura. Desde nuestra perspectiva el aspecto principal a resaltar es la necesidad de una cierta agregación de grupos familiares para la construcción de los diques, así como para la realización del evento de captura propiamente dicho. Situación que se ve compensada por la expectativa de obtención de grandes cantidades de alimento, considerando además que no existen evidencias -ni etnográficas ni arqueológicas- de algún tipo de procedimiento de conservación que permitiera diferir su consumo. Igualmente, dada la inversión de trabajo necesario, la cantidad de personas implicadas y las características de la captura, nos parece defendible caracterizar a estas ocasiones de captura masiva como eventos con un cierto grado de planificación.

También consideramos importante destacar que esta modalidad de captura de peces, si bien masiva, debe comprenderse como una técnica con ciertas restricciones. Por un lado, desde un punto de vista espacial la instalación de corrales estaría restringida a sectores protegidos del paisaje costero donde se conjuguen características como, la baja dinámica de mareas, fondos fangosos y en menor medida -considerando el caso de la isla Mary Annla presencia de desembocaduras de cursos de agua dulce de bajo caudal. Por otro lado, desconocemos cuán predecible podría haber sido la presencia de cardúmenes de peces de hábitos mixohalinos es estos lugares, lo que jugaría un rol importante en el grado de predictibilidad de tales recursos. En tal sentido cabe considerar la mención de Bridges sobre la expectativa que, con posterioridad a un evento exitoso transcurrirá mucho tiempo para que vuelvan a juntarse cantidades importantes de peces en el mismo sitio, así como la observación de Gusinde acerca de las pocas garantías de éxito que habría tenido esta técnica.

Para concluir, el hallazgo de estructuras de pesca en la costa norte del canal Beagle aporta nuevos datos a la evidencia existente sobre la diversidad de estrategias empleadas para el aprovechamiento de peces, amplia el espectro de variabilidad de las técnicas de obtención de recursos en general y nos permite dar un paso más en la caracterización del uso de los ambientes costeros en la región.

\section{AGRADECIMIENTOS}

A Ricardo Álvarez por brindarnos su estimulo durante la redacción de este trabajo y permitirnos mencionar en este artículo datos propios aun sin publicar sobre la ubicación de las estructuras de Vuelta del Perro, cercanías de Puerto Navarino y Seno Grandi.

A Denis Chevallay, por el aporte de datos inéditos como el de Bahía Douglas, por darnos acceso a imágenes de su archivo fotográfico y por las respuestas a diversas preguntas sobre algunos datos erráticos y la geografía de la Isla Navarino.

A Adrian Roca por habernos brindado la información inicial sobre el corral de Puerto Pescador.

A Pablo Smith por habernos informado de la presencia de la estructura de pesca de la isla Mary Ann. 
A Fernando Santiago por la colaboración en las tareas de campo.

A Ernesto Piana y Natalie Goodall por compartir información.

\section{BIBLIOGRAFIA}

Alvarez, R., Munita, D., Fredes, J., \& Mera, R. (2008). Corrales de pesca en Chiloé. Valdivia: Editorial América.

Andersen, S. H. (1995). Coastal adaptation and marine exploitation in Late Mesolithic Denmark - with special emphasis on the Limfjord region. En A. Fischer (Ed.), Man and Sea in the Mesolithic. Coastal Settlement Above and Below the Present Sea Level (pp. 41-66). Oxford: Oxbow Books.

Bannerman, N., \& Jones, C. (1999). Fish-trap types: a component of the maritime cultural landscape. The International Journal of Nautical Archaeology, 28(1), 70-84.

Bridges, L. ([1947] 2000). El último confín de la tierra. Buenos Aires: Editorial EMECÉ.

Bridges, L. (1947). Uttermost part of the Earth. Londres: Hodder and Stonghton.

Caminos, R. (1980). Cordillera fueguina. En Geología Regional Argentina Vol. II (pp. 1463-1501). Córdoba: Academia Nacional de Ciencias.

Cardillo, M., \& Scartascini, F. (2016). Possible Fishing Structures on the West Coast of San Matías Gulf, Río Negro, Patagonia Argentina. Journal of Island \& Coastal Archaeology, 11,1-5.

Constantinescu, F. (2005). Prospecciones arqueológicas en la costa noroeste de isla Navarino: resultados preliminares. En Libro de Resúmenes de las VI Jornadas de Arqueología de la Patagonia (pp. 3738). Punta Arenas: Ediciones CEQUA.

Coronato, A., Salemme, M., \& Rabassa, J. (1999a). Palaeoenvironmental conditions during the early peopling of Southernmost South America (Late Glacial-Early Holocene, 14-8 ka B.P.). Quaternary International, 53/54, 77-92.

Coronato, A., Rabassa, J., Borromei, A., Quatroccio, M., \& Bujalesky, G. (1999b). Nuevos datos sobre el nivel relativo del mar durante el Holoceno en el canal Beagle (Tierra del Fuego, Argentina). En Libro de resúmenes del I Congreso Argentino de Geomorfología y Cuaternario (pp. 27-28). Santa Rosa.

Decima, E., \& Dincauze, D. (1998). The Boston Black Bay Fish Weirs. En K. Bernick (Ed.), Hidden Dimensions: The Cultural Significance of Wetland Archaeology (pp.
157-172). Vancouver: UBC Press.

Emperaire, J. (1963). Los nómadas del mar. Santiago: Ediciones de la Universidad de Chile.

Fiore, D., \& Zangrando, A. F. (2006). Painted fish, eaten fish: artistic and archaeofaunal representation in Tierra del Fuego, Southern South America. Journal of Anthropological Archaeology, 25, 371-389.

Furlong, C. W. (1917). Tribal distribution and settlements of Fueguians, comprising nomenclature, etymology, philology, and population. The Geographical Review, III (3), 169-187.

Gallardo, C. R. ([1910]1998). Los onas de Tierra del Fuego. Buenos Aires: Zagier \& Urruty.

Gordillo, S., Bujalesky, G., Pirazzoli, P. A., Rabassa, J., \& Saliège, J. F. (1992). Holocene raised beaches along the northern coast of the Beagle Channel, Tierra del Fuego, Argentina. Palaeogeography, Palaeoclimatology, Palaeoecology, 99, 41-54.

Gusinde, M. (1986). Los Indios de Tierra del Fuego. Los yámana. Tomo II. Vol. 1. Buenos Aires: CAEA.

Johnston, R. B., \& Cassavoy, K. A. (1978). The Fishweirs at Atherley Narrows, Ontario. American Antiquity, 43, 697-709.

Legoupil, D. (2000). El sistema socioeconómico de los nómades del Mar de skyring (Archipielago de Patagonia). Anales del Instituto de la Patagonia, Serie Ciencias Humanas, 28, 81-120.

Lothrop, S. K. (1928). The Indians of Tierra del Fuego. New York: Contributions of the Museum of the American Indian. Heye Foundation.

López, H. L., García, M., \& San Román, N. (1996). Lista comentada de ictiofauna del canal Beagle, Tierra del Fuego, Argentina. Ushuaia: CADIC, Contribución Científica (Publicación Especial).

Lloris, D., \& Rucabado, J. (1996). Ictiofauna del canal Beagle (Tierra del Fuego): aspectos ecológicos y análisis biogeográfico. Madrid: Instituto Español de Oceanografía (Publicación Especial 8).

Malm, T. (1995). Submerged Stone Age sites in Denmark - the Tybrind Vig example. En A. Fischer (Ed.), Man and Sea in the Mesolithic. Coastal Settlement Above and Below the Present Sea Level (pp. 385-396). Oxford: Oxbow Books.

Martial, L. F., Deniker, J., \& Hyades, P. (2007). Etnografía de los Indios Yaghan en la Misión Científica del Cabo de Hornos 1882-1883. D. Legoupil \& A. Prieto (Eds.), Punta Arenas: Ediciones Universidad de MagallanesInstituto francés de Estudios Andinos.

Massardo, F., \& Rozzi, R. (2006). La etnoecologia más austral 
del planeta: artesanías y conocimiento ecológico tradicional Yaghan. Punta Arenas: Universidad de Magallanes-Fundación Omora.

Massone, M., Morello, F., Prieto, A., San Román, M., Martin, F., \& Cardenas, P. (2003). Sitios arqueológicos, restos de cetáceos y territorios locales Selk'nam en Bahía Inútil, Tierra del Fuego. Magallania, 31, 45-59.

McNiven, I. J., Crouch, J., Richards, T., Dolby, N., Jacobsen, G., Gunditj Mirring Traditional Owners Aboriginal Corporation. (2012). Dating Aboriginal stone-walled fishtraps at Lake Condah, southeast Australia. Journal of Archaeological Science, 39, 268-286.

Mobley, Ch., \& Mccallum, W. (2001). Prehistoric Intertidal Fish Traps from Central Southeast Alaska. Canadian Journal of Archaeology / Journal Canadien d'Archéologie, 25, 28-52.

Morello, F., Contreras, L., \& San Román, M. (1999). La localidad de Marazzi y el sitio arqueológico Marazzi I, una re-evaluación. Anales del Instituto de la Patagonia, Serie Ciencias Humanas, 27, 183-197.

Morello, F., San Roman, M., Prieto, A., Reyes, O., Bahamonde, G., Torres, J., \& Lucero M. (2008). Línea de base de recursos culturales y antecedentes históricos del área marina costera protegida Francisco Coloane. Punta Arenas: Centro de Estudios del Hombre Austral, Instituto de la Patagonia, Universidad de Magallanes.

Moss, M. L., \& Erlandson, J. M. (1998). A Comparative Chronology of Northwest Coast Fishing Features. En K. Bernick (Ed.), Hidden Dimensions: The Cultural Significance of Wetland Archaeology (pp. 180-198). Vancouver: UBC Press.

Moss, M. L., Erlandson, J. M., \& Stuckenrath, R. (1990). Wood Stake Weirs and Salmon Fishing on the Northwest Coast: Evidence from Southeast Alaska. Canadian Journal of Archaeology, 14, 143-158.

Munita, D., Alvarez, R., \& Ocampo, C. (2004). Corrales de piedra, pesca pasiva en la costa interior de Chiloé. Boletín de la Sociedad Chilena de Arqueología, 37, 61-74.

Nutley, D. (2006). The Last Global Warming? Survival in Australian Waters. Flinders University Maritime Archaeological Monograph Series, 10. Adelaide.

Orquera, L. A. \& Piana, E. L. (1992). Un paso hacia la resolución del palimpsesto. En Borrero, L. \& Lanata, J. (Coords.), Análisis espacial en la arqueología patagónica (pp. 21-52). Buenos Aires: Ayllu SRL.

Orquera, L. A., \& Piana, E. L. (1999a). Arqueología de la Región del Canal Beagle (Tierra del Fuego, República Argentina). Buenos Aires: Sociedad Argentina de
Antropología.

Orquera, L. A., \& Piana, E. L. (1999b). La vida material y social de los Yámana. Buenos Aires: Instituto Fueguino de Investigaciones Científicas. Editorial Universitaria de Buenos Aires.

Orquera, L. A., \& Piana, E. L. (2006). El poblamiento del área litoral sudamericana sudoccidental. Magallania, 34, 21-37.

Orquera, L. A., Piana, E. L., Fiore, D., \& Zangrando, A. F. (2011). Diez mil años de fuegos. Arqueología y etnografía del fin del mundo. Buenos Aires: Editorial Dunken.

Pedersen, L. (1995). 7000 years of fishing: stationary fishing structures in the Mesolithic and afterwards. En A. Fisher (Ed.), Man and Sea in the Mesolithic (pp. 75-86). Oxford: Oxbow Books.

Pickard, C., \& Bonsall, C. (2007). Late Mesolithic coastal fishing practices. The evidence from Tybrind Vig, Denmark. En B. Hårdh, K. Jennbert \& D. Olausson (Eds.), On the Road. Studies in Honour of Lars Larsson (pp. 176 183). Estocolmo: Acta Archaeologica Lundensia, 4(26).

Pedersen, J. B., Robinson, B. S., Belknap, D. F., Stark, J., \& Kaplan, L. K. (1994). An Archaic and Woodland Period Fish Weir Complex in Central Maine. Archaeology of Eastern North America, 22, 197-222.

Rabassa, J. O., Coronato, A., Bujalesky, G., Salemme, M., Roig, C., Meglioli, A., Heusser, C.,... Quattrocchio, M. (2000). Quaternary of Tierra del Fuego, Southernmost South America: an update review. Quaternary International, 68-71, 217-240.

Rabassa, J. O., Serrat, D., Marti, C., \& Coronato, A. (1990). Internal structure of drumnlins in Gable Island, Beagle Channel, Tierra del Fuego, Argentina. LUNDQUA Report, 32, 3-6.

Reyes Báez, O., San Román, M., \& Moraga, M. (2011). Archipiélago de los Chonos: nuevos registros arqueológicos y bioantropológicos en los canales septentrionales. Isla Traiguen, Región de Aisén. Magallania, 39(2), 293-301.

Santiago, F. (2013). La ocupación humana del norte de Tierra del Fuego durante el Holoceno medio y tardio. Ushuaia: Editora Cultural Tierra del Fuego.

Santiago, F., Oría, J., \& Salemme, M. (2007). Nuevo contexto arqueológico del Holoceno medio. Río Chico 1. Tierra del Fuego. Argentina. En Actas del XVI Congreso Nacional de Arqueología Argentina Tras las Huellas de la Materialidad (pp. 439-445). San Salvador de Jujuy: Editorial de la Universidad Nacional de Jujuy.

Skewes, J. C., Alvarez, R., \& Navarro, M. (2012). Uso 
consuetudinario, conflictos actuales y conservación en el borde costero de Chiloe Insular. Magallania, 40(1), 109-125.

Tivoli, A., \& Zangrando, A. F. (2011). Subsistence variations and landscape use among maritime hunter-gatherers. A zooarcheological analysis from the Beagle Channel (Tierra del Fuego, Argentina). Journal of Archaeological Science, 38, 1148-1156.

Torres, J. (2009). La pesca entre los cazadores recolectores terrestres de la Isla Grande de Tierra del Fuego, desde la prehistoria a tiempos etnográficos. Magallania, 37(2), 109-138.

Vázquez, M., Zangrando, A. F., Tessone, A., \& Ceraso, A. (2011). Arqueología de la costa meridional de Península Mitre. En A. F. Zangrando, M. Vázquez \& A. Tessone (Eds.), Los cazadores-recolectores del extremo oriental fueguino Arqueología de Península Mitre e Isla de los Estados (pp. 203-230). Buenos Aires: Sociedad Argentina de Antropología.

Zangrando, A. F. J. (2003). Ictioarqueologia del canal Beagle. Explotación de peces y sus implicaciones en la subsistencia humana. Buenos Aires: Sociedad Argentina de Antropología. Colección Tesis de licenciatura.

Zangrando, A. F. J. (2007). Long-term variations of marine fishing at the southern end of South America: perspectives from Beagle Channel Region. En H. Hüster Plogmann (Ed.), The Role of Fish in Ancient Time (pp. 17-23). Rahden / Westf, Verlag Marie Leidorf.

Zangrando, A. F. J. (2009a). Historia evolutiva y subsistencia de cazadores-recolectores maritimos de Tierra del Fuego. Buenos Aires: Sociedad Argentina de Antropología. Colección tesis Doctorales.

Zangrando, A. F. J. (2009b). Is fishing intensification a direct route to hunter-gatherer complexity? A case study from the Beagle Channel region (Tierra del Fuego, southern South America). World Archaeology, 41(4), 589-608.

Zangrando, A. F. J., \& Tivoli, A. (2015). Human use of birds and fish in marine settings of southern Patagonia and Tierra del Fuego in the Holocene: A first macro-regional approach. Quaternary International, 373, 82-95. 